ARTIGOS 



\title{
Entre capas e letras, embates e crenças 20 anos de Pro-Posições
}

\author{
Agueda Bernardete Bittencourt * e Elizabeth Mercuri **
}

O nome de uma revista remete a um conjunto de coisas que ultrapassam o objeto nomeado. Aparecem com o nome: os editores, os autores, a forma, as cores, o lugar de origem, o status. Dados que vão se construindo no contato com esse objeto, sem que se perceba como, sem que alguém faça deliberadamente uma política para essa construção de imagem, ou talvez porque se faça essa política deliberada.

A história de uma revista escreve-se analisando a sua relação com outras que operam no mesmo campo, com as quais se alia ou concorre, nas quais se inspira, das quais copia modelo ou se distancia. No caso de uma revista universitária, não se pode deixar de considerar o lugar de publicação, dado que a revista carrega a marca da instituição que a mantém. O quadro de dirigentes e editores; os autores mais publicados; os temas abordados; a linha editorial; a capa e a qualidade do objeto - o papel, a impressão; os lugares de circulação: feiras em congressos, portais eletrônicos, livrarias - todos esses elementos definem o lugar e o valor atribuídos em determinado momento a uma revista, em relação às demais em circulação.

Uma revista é uma produção da cultura, revela uma época, um pensamento, uma forma de expressão de um grupo ou de uma instituição; revela lutas, vitórias e derrotas, de idéias e de pessoas. Estudar uma revista pode ser o acompanhar dos movimentos de redes que se tecem e se desmancham, suas fantasias e suas crenças, os embates pelos poderes e, especialmente, pelo poder da palavra, esta que tem a faculdade de nomear e de fazer existir.

Hoje são muito populares os estudos sobre revistas acadêmicas ou científicas de circulação periódica, graças às políticas de financiamento e de avaliação desses objetos pelos órgãos oficiais reguladores e avaliadores de tudo o que se

\footnotetext{
* Pesquisadora do Departamento de Educação, Conhecimento, Linguagem e Arte e membro do Grupo de pesquisa sobre instituição escolar e organizações familiares (Focus) da Faculdade de Educação da Unicamp, Campinas, SP, Brasil. agueda. bittencourt@gmail. com

*** Professora colaboradora da Faculdade de Educação da Unicamp. emercuri@unicamp.br
}

Agradecemos à generosidade de Ana Maria Fonseca de Almeida e Martha Cecilia Herrera de cuja leitura, sugestôes e críticas este artigo se beneficiou. 
refere à educação e à cultura. Aqui, o interesse em compreender a avaliação e seus critérios deve-se ao poder que tal classificação oficial, derivada da avaliação, tem de lançar a revista em portais eletrônicos de acesso internacional e de alta repercussão no mundo acadêmico, definindo a sobrevivência das revistas.

Nossa proposta, entretanto, é de compreender ou imaginar - pelos traços deixados em quase 60 números, a partir de diferenças e oposições que colocam frente a frente revistas e editores - a história de uma revista, cujo lugar no mundo acadêmico foi conquistado e consolidado ao longo de duas décadas. Pretendemos elaborar dados e interpretações que dialoguem com os trabalhos que escrevem a história da educação, da cultura institucional e da produção acadêmica brasileira.

Cabe esclarecer, para o bem da análise e em respeito ao leitor, que nós, autoras deste artigo, contamos com experiência diferenciada e envolvimento com a revista ao longo da história. Ambas fomos membros da comissão editorial, de 2000 a 2009, protagonizando, portanto, os acontecimentos e participando da definição da política editorial e do rumo do periódico. Além dos traços deixados nos números da revista, contamos, para esse período, com as lembranças e as memórias da experiência vivida.

Este estudo toma as revistas acadêmicas como manifestaçōes culturais que se produzem na fronteira de duas lógicas: a da produção erudita e a da indústria cultural. A primeira tende a produzir ela mesma suas normas e seus critérios de avaliação, e a segunda obedece às leis da concorrência para conquista do mercado. $\mathrm{O}$ texto considera, ainda, a regulação operada pelos órgãos públicos sobre a educação e a cultura. Aqui se trata do universo de produção de bens especiais que mobiliza "o sistema de relações objetivas entre diferentes instâncias definidas pela função que cumprem na divisão do trabalho de produção, de reprodução e de difusão de seus bens simbólicos"1.

\section{Revistas de educação}

A revista Pro-Posiçôes foi criada na Faculdade de Educação da Unicamp na década seguinte àquela em que foram fundadas as primeiras revistas em universidades públicas ou privadas, frutos da institucionalização das faculdades de educação e dessa área de pesquisa nas universidades brasileiras.

Existiam, nessa época, algumas revistas em circulação, como: Cadernos de Pesquisa, ligada à Fundação Carlos Chagas, criada em 1971; Educação e Pesquisa, da Faculdade de Educação da USP, de São Paulo; Educação e Realidade, da Faculdade de Educação da Universidade Federal do Rio Grande do Sul; Educação em

$\overline{\text { I. }}$ Bourdieu (2007, p. I I 5). 
Debate, da Universidade Federal do Ceará, aliadas à Revista Brasileira de Estudos Pedagógicos - RBEP — do Instituto Nacional de Estudos e Pesquisas Educacionais, a mais antiga revista da área em circulação. Na Unicamp, foi criada a revista Educação \& Sociedade, que marcou o campo editorial da educação, apresentando-se como uma nova forma de fazer publicação periódica, de forma independente, com circulação e captaçãoo de artigos no âmbito nacional, posicionandose dentro e fora da universidade ${ }^{2}$. Todas as revistas criadas no período respondiam aos anseios pelo debate reprimido nos 20 anos de regime autoritário.

$\mathrm{Na}$ década seguinte, foram criados alguns novos títulos, que persistem ainda hoje, entre eles: Em Aberto, também ligada ao INEP, Educação em Revista, da Faculdade de Educação da Universidade Federal de Minas Gerais e Revista $A N D E$, da Associação Nacional de Educação. Esta última deixou de circular no início da década de 1990. Desde então, o número de novas revistas não tem parado de crescer: há dez anos falava-se em 350 títulos, e hoje se faz referência a mais de mil.

\section{Cada criação, um grupo criador}

Tentaremos apresentar a revista Pro-Posiçôes em relação às demais revistas da área, criadas na Universidade de Campinas. A revista Educação \& Sociedade foi a primeira delas a surgir. Distinguia-se por ser uma revista editada por um centro de estudos, apresentar conselho editorial composto de professores de distintas áreas e de âmbito nacional e por manter-se, em boa medida, mas não inteiramente, com recursos próprios, independente da Universidade que a acolhia e lhe oferecia infra-estrutura. Sobreviver independente das hierarquias institucionais representava uma posição política respeitável. Especialmente se tomamos em conta que todas as demais revistas de educação, em circulação na época, eram criaçóes oficiais.

$\mathrm{Na}$ Faculdade de Educação da Unicamp, o grupo que criou a revista Educação \& Sociedade e o próprio centro de estudos que até hoje a mantém era composto por professores de ciências sociais, história e filosofia, áreas representativas da resistência ao regime autoritário e reconhecido como um grupo progressista, com capacidade de articular redes de relações para além da institui-

2. Educação \& Sociedade foi criada por um grupo de professores da Faculdade de Educação da Unicamp; não a representava institucionalmente, embora a ela estivesse sempre relacionada. Dois fatores foram muito importantes para a construção da imagem de revista independente de que goza a Educação \& Sociedade. Primeiro, ela foi criada no mesmo momento (1978) e lugar onde se organizou a volta às Conferências Brasileiras de Educação, um forte movimento intelectual e político que marcou o fim da ditadura militar e a retomada das discussões com vistas às reformas do ensino, que deveria eliminar as marcas do período autoritário na educação brasileira. 
ção onde atuava. O capital de relações sociais manipulado por esse grupo fundador, que tinha entre seus membros ex-exilados recém-chegados da Europa, ex-presos políticos e militantes ligados a partidos de esquerda, garantiu a projeção da revista desde os seus primeiros números ${ }^{3}$.

Afirmavam os criadores, em seu primeiro número, que a revista Educação \& Sociedade pretendia ser uma revista preocupada com a análise da realidade brasileira, abrindo o seu espaço para propostas intelectuais, no que se referia tanto às técnicas, às doutrinas e às práticas educacionais, como à reflexão sobre o seu impacto na sociedade como um todo: uma revista que tivesse como foco a perspectiva da teoria e da prática no âmbito do conhecimento sócio-educativo, procurando recuperar certa informação histórica dessa prática e dessa teoria, sem deixar de responder aos problemas postos pela educação brasileira contemporânea ${ }^{4}$.

A criação da revista Pro-Posiçôes deu-se de forma distinta dessa. Nasceu de um projeto do grupo representado pelo diretor da Faculdade de Educação, José Dias Sobrinho, e foi assumida por uma comissão editorial que deu forma e conteúdo ao periódico nascente. Faziam parte dessa comissão professores com experiência de formação em universidades estrangeiras e com representação dos diferentes ramos do conhecimento em educação. ${ }^{5}$

Projetada para publicar a produção de seus professores e estudantes e divulgar as realizações da Faculdade de Educação, a revista foi apresentada pelo diretor José Dias Sobrinho como um espaço para o debate de posiçôes divergentes, de formulação de propostas de intervenção na realidade educacional e como um lugar de exposição de idéias e compromissos políticos com a sociedade. O projeto da revista foi divulgado no Editorial do número 1:

Pro-Posiçôes: mais um canal de debates sobre questôes educacionais [...] terá a cara da Faculdade que a propõe como revista... Quer ser prospectiva, quer (a)firmar suas posiçōes, quer propor forma de interveniência na prática social educativa. Mostra (e camufla) as contradiçôes vividas, marca de um tempo...

O editorial ressaltava que, antes mesmo de atingir os setores da sociedade a que se dirigem, os trabalhos científicos cumprem importante papel na organização das discussões e das pesquisas que dão forma aos pólos de produção intelectual. O projeto afirmava que a Revista poria a público as divergências no campo da ciência, a pluralidade nos modos e nos lugares da prática política, as

3. Ivany Pino, Maurício Tragtenberg, Evaldo Amaro Vieira, Antônio Muniz de Resende, Pedro Goergen, Milton José de Almeida, Elizabeth Pompeo de Camargo, Eloísa de Mattos Hoffling.

4. "Apresentando nosso compromisso", Educação \& Sociedade (I 978, p. 3).

5. Ezequiel Theodoro da Silva, Márcia Ferreira de Brito, Newton Aquiles Von Zuben, José Camilo dos Santos Filho e Lúcia Mercês de Avelar, além da colaboração de Milton José de Almeida. 
distintas concepçóes educacionais. E, antes de concluir com os agradecimentos de praxe, o editorial referiu-se à revista que acabava de ser criada como: "uma forma de a universidade prestar contas de seu trabalho à sociedade"6.

A folha de rosto do número 1 é também reveladora da concepção de revista que surgia. Nela aparece, além do nome e do endereço da revista, toda a hierarquia da Universidade, desde o reitor, passando pelo chefe de gabinete e pelos pró-reitores. Da Faculdade de Educação são referenciados o diretor, o vicediretor e todos os coordenadores de cursos. Essa localização institucional tão marcada era uma opção que nem todas as revistas institucionais assumiam ${ }^{7}$.

Não existia conselho editorial, nos primeiros números; apenas havia uma comissão de redação, composta por um professor de cada departamento, e um jornalista responsável, marca dos tempos de regulamentação da profissão de jornalista. Como a revista se voltava para a publicação da produção científica da Faculdade, todo o seu corpo docente compunha o quadro de colaboradores permanentes, e seus artigos não passavam por referees. A revista era produzida pela Cortez Editora, uma casa editorial especialmente dedicada a publicações de educação.

Linha editorial: número temático, dossiês, autores ...

A partir do segundo número, a revista assumiu o formato que se manteria por um longo período. O professor José Camilo dos Santos Filho assumiu a editoria e permaneceu nessa função, por sete anos, até a publicação do número 22. Nesse período, a revista publicou principalmente quatro seções: de artigos, de resenhas, de resumo de teses e dissertações e uma seção especial para divulgar eventos da área promovidos pela Faculdade de Educação da Unicamp ou envolvendo seus professores, além de um editorial escrito pelo editor ou por algum membro da comissão editorial que, em geral, fazia a apresentação dos artigos e dos autores que compunham aquele número.

A revista foi se consolidando e assumindo aos poucos o padrão comum das revistas da área. Logo nos primeiros números, apareceu a comissão editorial; o sumário em inglês começou a ser publicado no terceiro número, e os indexadores apareceram na revista de número 5 . O conselho editorial composto por pesquisadores estrangeiros surgiria depois de cinco anos de circulação da revista, no número 15 , indicando que a estruturação básica estava completa. A revista foi indexada nos principais indexadores da área, o que garantiu, em certa medida, sua existência pública e sua longevidade.

6. Dias Sobrinho, J. "Editorial", Pro-Posições, n. I, v. I, p. 5.

7. Entre as revistas: RBEP, Cadernos de Pesquisa, Educação em Debate, Educação e Pesquisa, encontramos referências a uma ou duas das autoridades institucionais, diferentemente da ProPosições, que referenciava uma dezena delas. 
Duas seções marcaram a política editorial dos primeiros anos: a seção de Resumos de teses e dissertações e a de Divulgação de eventos. A primeira publicava o nome da tese, do autor e do orientador e um resumo do trabalho defendido na Faculdade de Educação da Unicamp. Nas revistas consultadas para esta pesquisa, não encontramos nenhuma seção similar a esta da Pro-Posiçôes. Em tempos de ainda pouco uso das novas tecnologias de informação, essa seção cumpria a tarefa de divulgar o programa de pós-graduação, sua produção, suas áreas de pesquisa e seus pesquisadores. Proposta importante para a Faculdade de Educação da Unicamp, que nesse período já gozava de muito prestígio, exibia reconhecimento nacional e recebia estudantes de todo o Brasil. Esse lugar central no cenário nacional foi sendo, durante a década de 1990, compartilhado com outras instituiçôes, graças à abertura de programas de pósgraduação em universidades do Nordeste, Norte e Centro-Oeste do País, de onde, até então, chegavam grandes contingentes de estudantes para a Unicamp. Entretanto, até a revista número 22 ainda apareceu a seção Resumo de teses e dissertaçôes.

A seção Divulgação é reveladora da cultura editorial da área, da política de divulgação que era usada também por outras revistas, como a Revista Brasileira de Estudos Pedagógicos e a Educação \& Sociedade: ambas mantiveram uma seção jornal que dava notícias dos eventos mais importantes a partir do ponto de vista dos editores e de suas comissões. Na revista Pro-Posiçôes, essa seção divulgava relatos de viagens internacionais de professores, encontros acadêmicos realizados ou programados na Faculdade, concursos e cerimoniais de titulação, além de manifestos políticos. Tomamos aqui como exemplo a seção publicada na revista número 4, onde aparecem: o Memorial de concurso do professor Maurício Tragtenberg; a Manifestação da Faculdade de Educação sobre o Programa Alfabetização e Cidadania; um Convênio realizado entre a Unicamp e a Universidade de Lujan, na Argentina; um Informe sobre a VII Reunião da ANPEd, pelo professor Saviani; a notícia do Seminário sobre as novas tecnologias e a formação do trabalhador: a questão da politécnica, realizado na Faculdade de Educação; o relato de viagem de estudos ao Canadá, escrito pelo prof. José Camilo dos Santos Filho e o relato de viagem de estudos à França, apresentado pela professora Sarita Moyses. No número seguinte, além das notícias sobre encontros acadêmicos, foi publicada a nota sobre a criação dos cursos noturnos na Unicamp e sobre a visita da professora Christiane Gillièron, da Universidade de Genebra. Essa espécie de jornal da educação oferecia uma visão do movimento e das práticas acadêmicas e políticas na universidade.

A seção Resenhas era alimentada, principalmente, por trabalhos de pósgraduandos, em sua maioria destinados a apresentar os lançamentos do mercado editorial, na área de educação. 
Quanto à seção Artigos, a parte mais importante da revista nos 22 primeiros números, manteve-se, em distintos formatos. Começou com artigos de balcão, logo publicou dois números com os textos do seminário "Um século de educação republicana”. Foram organizados alguns números temáticos, outros com dossiês, até que se definiu que um número anual seria temático e os demais, organizados com os artigos de balcão.

Entre os autores presentes nos primeiros números, estavam majoritariamente - cerca de $70 \%$ — professores e estudantes de pós-graduação da casa, característica esta que prevaleceu nos primeiros 5 anos e que, gradativamente, foi se alterando, até atingir um percentual em torno de $25 \%$, nos números mais recentes. Os autores brasileiros não ligados à Unicamp eram em torno de $25 \%$ nos primeiros 5 anos, passando para 35\% nos anos seguintes e estabilizando-se em aproximadamente $55 \%$. Os estrangeiros presentes entre os autores da revista eram $5 \%$ nos primeiros anos, chegaram a $25 \%$ e hoje são, em média, 20\% dos autores publicados.

Os temas abordados eram os mais diversos, assim como o era, na Faculdade, o leque temático da pesquisa, marcada por um tipo de trabalho fortemente individualizado. Não chegaram a aparecer polêmicas e debates previstos ou esperados pelos fundadores da revista. Uma seção chamada Debates, espaço de réplica aos artigos, chegou a ser criada e anunciada no editorial da revista número 10, para início no número seguinte, mas não foi ativada. Uma observação importante é o espaço de publicação para autores de língua espanhola, desde os primeiros números da revista. São eles que respondem por boa parte dos, em média, $20 \%$ de autores estrangeiros. O fato de publicar artigos em português e espanhol, sem tradução, é um dos fatores que pode explicar essa relação, mas não se pode desconhecer também que a existência de um número considerável de estudantes de pós-graduação, vindos dos países vizinhos, de língua espanhola, pode ter forçado a opção por uma revista em duas línguas. Assim, vale ainda lembrar a presença dos professores argentinos e colombianos na Faculdade de Educação.

\section{Mudanças e rearranjos}

A trajetória da revista foi marcada por um período de forte crise, entre o número 22 e o 34, de 1997 a 2002, revelado na perda de periodicidade, com atraso que chegou a cinco números. Foi quando se deu uma mudança quase total dos membros da comissão editorial e do editor.

Era uma crise de caráter econômico, de falta de estrutura operacional, de ausência de pessoal especializado para a sua produção. Estes eram problemas comuns a todas as revistas da área. A Educação e Pesquisa, da Faculdade de 
Educação da USP, por exemplo, quase fechou nessa época. Teve uma interrupção de circulação e foi completamente reformulada. A Pro-Posiçôes, entretanto, reformulou-se sem interromper a circulação. A comissão editorial, apoiada pela nova equipe dirigente da Faculdade, assumiu a responsabilidade de produzir, no mais breve tempo possível, os cinco números que estavam atrasados. Por essa razão, não apenas os cinco, mas os dez números seguintes foram organizados na forma possível, para garantir que o periódico não fechasse. Esses números obedeceram a distintos formatos: ora temáticos, ora com dossiê ou com seçôes novas, mas já com nova capa, nova imagem; todavia, com padronização prejudicada.

A criação e o fechamento de revistas na área de educação foram comuns depois dos anos setenta. Freqüentemente apareceram revistas que não passaram do terceiro número. Na própria Faculdade de Educação, houve uma que se chamou Entretextos, entresexos, com apenas quatro números, e uma segunda chamada Trajetos, que também não chegou a uma dezena de números. Surgiu, em 1993, a Zetetiké, revista especializada em Educação Matemática, hoje estabelecida e gozando de prestígio em sua área, mas que, baseada apenas no esforço dos próprios professores do grupo de pesquisa que a publica, enfrentou dificuldades para manter-se. Ainda na Unicamp, em meados dos anos noventa, criada pelo mesmo idealizador da Pro-Posiçôes, José Dias Sobrinho, surgiu a revista Avaliação, que se mantém hoje com o apoio da Universidade de Sorocaba, para onde migrou, juntamente com professores aposentados da Faculdade de Educação da Unicamp ${ }^{8}$. Mais recentemente, foram criadas algumas revistas virtuais na Faculdade de Educação da Unicamp?. Assim, criou-se em três décadas, uma dezena de revistas, das quais pelo menos a metade sobrevive, muito bem reconhecida.

A Pro-Posiçôes foi impactada ainda por mudanças políticas na direção da Faculdade de Educação, o que levou os responsáveis a enfrentarem um processo de ampliação da comissão editorial e reformulação da revista, de montagem

8. "Desde março de 2007 (v. 12, n. I), Avaliação vem contando com o apoio institucional da Universidade de Sorocaba. Esse apoio institucional decorre de uma parceria entre a RAIES Rede de Avaliação Institucional de Educação Superior, associação civil sem fins lucrativos, que vem editando desde 1996 a Revista Avaliação, e a Uniso — Universidade comunitária, fortemente comprometida com objetivos sociais. [...] Desde 1996, com rigorosa pontualidade, esta Revista vem colaborando para conferir densidade e importância à área de estudos de educação superior e, especialmente, de avaliação da educação superior, no Brasil e na América Latina." (Dias Sobrinho, 2007).

9. Além da revista Pro-Posições, da Educação \& Sociedade, da Zetetiké, circulam hoje, produzidas na Unicamp, as seguintes revistas virtuais, da área de educação: Filosofia e Educação - Revista Digital do Grupo de Estudos e Pesquisas Paidéia; Ciência e Ensino; Ciências em Foco; Revista Histedbr On-Line; Educação Temática Digital. 
de infra-estrutura para edição, com pessoal especializado, que só se completaria cinco anos mais tarde.

Mas é importante ressaltar que o próprio campo das publicações periódicas em educação sofreu mudanças nesse final dos anos noventa. Se comparadas com as publicações das áreas científicas, as da educação são muito novas e não dispõem do status daquelas. Como atividade nova, os periódicos das humanidades tinham que inventar as formas de fazer e de legitimar-se perante a comunidade acadêmica e perante a sociedade; isso ocorreu no mesmo momento em que se deu a expansão e o aprofundamento do sistema de avaliação institucional das universidades brasileiras e, com ele, a expansão da avaliação de toda criação acadêmica pelos órgãos governamentais como Capes, CNPq, Fapesp, entre outros. Por outro lado, nas ciências humanas, cujos resultados de pesquisa estiveram sempre mais expressos nos textos longos, publicados em livro, o espaço das revistas começou a mostrar-se atrativo, contaminadas que foram pelo movimento da comunidade científica nacional e internacional. "Em um quadro crescente de produção científica que se materializa principalmente em artigos, a avaliação do periódico e da comunidade de pesquisa é uma exigência de mercado" 10 .

Nessa fase da revista Pro-Posiçôes, algumas decisões foram tomadas, aprofundando uma tendência, já em curso, de acolher artigos — de autores externos à Faculdade de Educação - que fossem relevantes para o debate na área e que resultassem de pesquisas e estudos originais, no conteúdo e na forma. Passou-se a pensar em seções novas, adequadas para colocar em circulação toda ordem de discurso, em palavras ou em imagens, que estivesse no cenário da educação. Ser uma revista aberta e com capacidade de reinventar-se parecia ser a sua vocação. Talvez porque gerar distinções seja a arte de sobrevivência no campo intelectual ${ }^{11}$.

As políticas para as universidades passaram a exigir que os resultados de estudos e de pesquisas fossem socializados rapidamente, circulassem em âmbito nacional e internacional. Assim, a Pro-Posiçôes reinventava-se, procurando manter-se em sintonia com as tendências do campo editorial em que está inserida. Ela ganhou novo conselho editorial nacional e internacional, nova comissão editorial ampliada e não mais ligada à representação departamental e uma infra-estrutura composta por um editor técnico e uma secretaria.

Estabeleceu-se um formato estável que associou quatro seções: Artigos, Dossiê, Diverso e Prosa e Resenhas. A seção Artigos constitui-se no espaço reservado ao pensamento elaborado pela comunidade acadêmica da área e submetido livre-

10. Cf. Miranda e Pereira (1996, p. 376).

I।. Gustavo Sorá (1997, p. |5|-|8|). 
mente pelos seus autores, para publicação segundo os padrōes de qualidade e relevância estabelecidos pela comissão editorial, após a avaliação de referees; os Dossiês, encomendados ou propostos por pesquisadores da área e de responsabilidade do proponente ou do convidado, são avaliados pela comissão editorial. É o Dossiê que nomeia o número da revista e responde por cerca de $50 \%$ de suas páginas. Ao examinar em detalhe os dossiês temáticos publicados, pode-se afirmar que a revista Pro-Posiçôes acolhe um maior número de autores externos à Faculdade de Educação da Unicamp, sem, contudo, perder a direção da política editorial, marcada, em boa medida, por esses dossiês, coordenados pelos pesquisadores da casa. São estes que trazem para a revista os componentes de suas redes nacionais e internacionais.

A tradicional seção Resenhas, mantida desde a criação, é talvez a única que não sofreu alteração alguma, a não ser, recentemente, uma pequena alteração no nome, passando a chamar-se: Leituras e Resenhas, sem que isso tenha significado alteração do conteúdo ou mesmo da forma. A seção Diverso e Prosa foi projetada como um espaço para publicação de artigos esgotados, documentos inéditos ou que circularam apenas em língua estrangeira; ou, ainda, de textos antigos, porém inéditos, cartas, entrevistas ou outros documentos de interesse dos educadores e dos pesquisadores. Tem-se mantido como um espaço de expressão da própria comissão editorial, assim como o próprio Editorial, que expõe a posição política da revista, discutindo um tema da atualidade. Chegaram ainda a ser publicados alguns textos sob a rubrica Ensaios e outros sob a rubrica Traduções, seções estas que não prosperaram.

A consolidação do modelo de periódico com um dossiê temático é tributária, em certa medida, também do movimento do campo da pesquisa em educação, hoje organizado em grupos regulamentados pelo CNPq e pela Capes, que sustentam academicamente os programas de pós-graduação e os grupos de trabalho da Anped e que alimentam as revistas. Eles fazem circular as reflexóes realizadas na área de educação e demonstram as redes de cooperação nacionais e internacionais. Novos temas, como: linguagens, imagens, corpo, saúde, educação estética, literatura, teatro, educação do olhar, violência, sexualidade e gênero, juventude e memória juntaram-se aos já tradicionais: escolarização, ensino superior, reformas de ensino, currículos, educação infantil, para expressar o movimento da pesquisa nas redes em que se insere a Faculdade de Educação da Unicamp.

\section{livro, a estética, as normas...}

O nome da revista foi escolhido, conforme cabia a uma revista institucional, por um concurso interno e chegou como uma palavra só - Proposiçóes - capaz 
de indicar, já no título, a pluralidade de posiçōes que se pretendia fazer circular. $\mathrm{O}$ artista encarregado de criar a imagem da revista sugeriu converter o nome em uma palavra composta, deixando ainda mais clara a idéia de uma revista em prol do debate de posiçóes diversas.

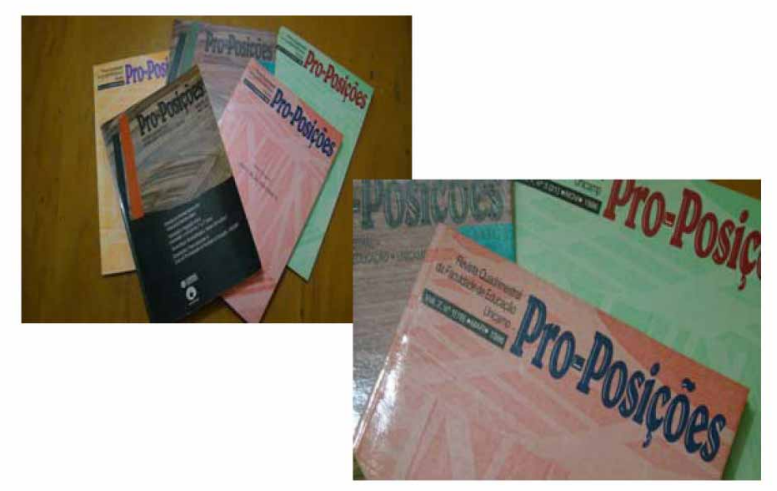

Os primeiros 20 números circularam com uma capa padrão, inicialmente impressa em quatro cores, que variavam a cada número, embora o mesmo não ocorresse com a gravura, que foi alterada apenas duas vezes. Era plastificada no modelo com brilho e trazia o Sumário, na primeira e na quarta capa, além dos logotipos da Faculdade de Educação e da Unicamp. Os números 23 e 24 foram os únicos que tiveram a capa impressa em uma cor só. Percebe-se, nessa fase, um envolvimento maior com a preparação de uma publicação correta, dentro das normas e da expectativa dos autores e dos leitores, sem maior preocupação com a estética do livro. $\mathrm{O}$ miolo, impresso em duas colunas bem distribuídas na página, iniciava-se com a folha de rosto em geral sobrecarregada, com muitas informações e com fragmentos da gravura de capa.

As capas da revista revelam sua trajetória, como também o movimento do campo editorial da educação ${ }^{12}$. Os anos oitenta foram responsáveis pela criação de programas de pós-graduação em boa parte das universidades públicas brasileiras, fazendo com que a produção de pesquisa se expandisse muito rapidamente e, com ela, os espaços de publicação. Esse primeiro momento impactou as editoras. As teses de doutorado e de mestrado converteram-se em livros para satisfazer um mercado em expansão. Na década seguinte, foi a vez das revistas criadas nas universidades para dar vazão à produção crescente. Passou-se a contar as revistas às centenas.

O impacto dessa expansão sobre a revista Pro-Posiçôes pode-se observar também no seu aspecto estético, com as mudanças ocorridas no final da década de 1990. A partir do número 25 , no oitavo ano de circulação, o periódico foi

12. Gustavo Sorá (1997). 
transformado. Ganhou novas dimensōes, perdendo o aspecto tradicional de revista e aproximando-se do formato de livro, com maior número de páginas e novo layout.

Essa mudança configura uma transformação importante, operada desde o universo simbólico. A semelhança com o livro desloca para a revista, no imaginário do leitor, algumas das características desse objeto. A revista flexível, de dimensões maiores e com menor número de páginas, carrega a idéia de um objeto de leitura rápida e de certa forma descartável, ou, pelo menos, de uso em tempo breve, como é o caso das publicaçóes mensais ou semanais de divulgação. O livro, por sua vez, incorpora a idéia de objeto durável, de leitura recorrente, cujo valor simbólico marca o mundo intelectual. Ele, que já teve capa de material nobre como o couro, com desenhos em ouro, onde a beleza tinha seu lugar - como hoje se vê nas criaçóes recentes da editora Cosac Naify ou da Companhia das Letras, para livros de literatura - distancia-se do descartável e passageiro ${ }^{13}$.

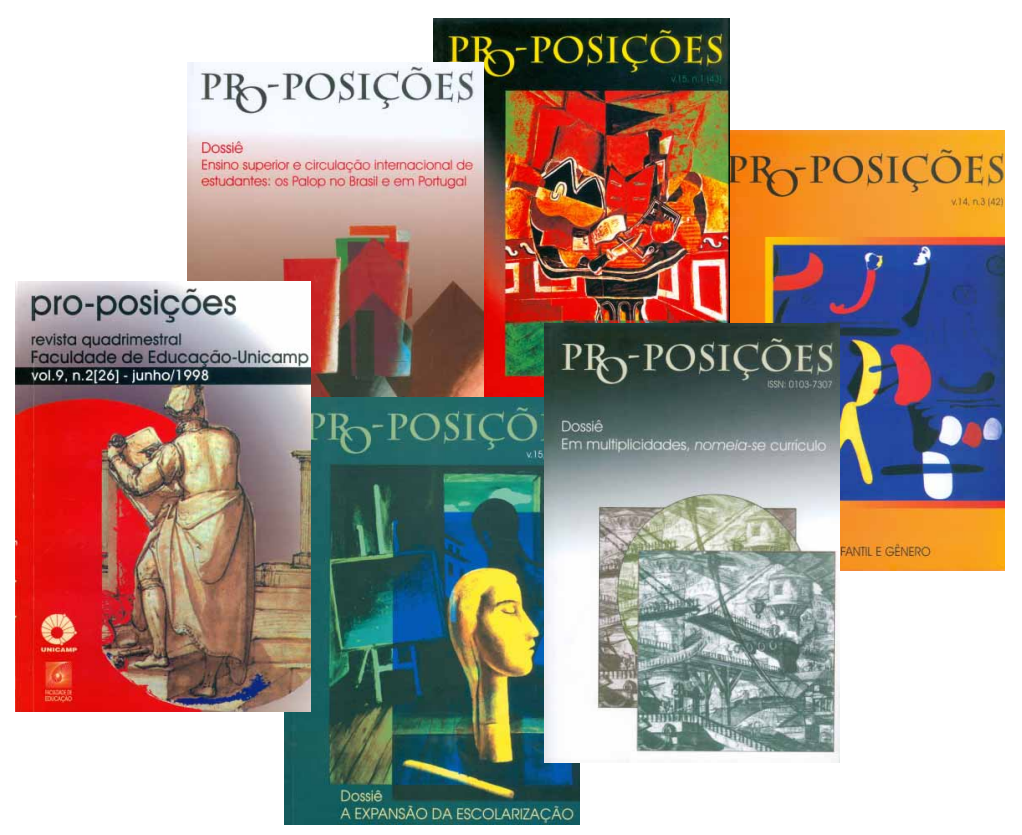

Alterada a diagramação, a capa nova ganhou também, além do formato, um projeto artístico que, inicialmente, foi concebido para marcar os volumes anu-

13. Ver, sobre este assunto, os trabalhos de Gustavo Sorá, Heloísa Pontes e de Pierre Bourdieu, especialmente deste último (Bourdieu, 2007). 
ais. $\mathrm{O}$ artista propôs uma criação nova para cada ano, cuja imagem teria suas cores alteradas a cada número. Essa proposta, questionada pelo representante da editora que deveria distribuir a revista, vigorou apenas por dois anos ${ }^{14}$. Segundo esse editor, a manutenção da imagem em três números não chamaria a atenção do leitor a cada novo lançamento, o que prejudicaria a distribuição. Assim, do número 31 em diante, a revista ganhou uma criação artística para cada número.

Nova mudança no aspecto da revista ocorreu quando aos poucos se operou uma "limpeza na imagem", restringindo-se ao máximo as informações na primeira capa, trocando-se o papel branco do miolo e substituindo-se a mancha densa por uma distribuição mais arejada dos caracteres na página. A cobertura de plástico brilhante deu lugar à cobertura fosca, de aparência mais bonita e manuseio mais agradável. Essas alterações acompanharam uma tendência verificada na aparência dos livros de editoras de maior prestígio no mercado editorial. Na sua apresentação física, a Pro-Posiçôes quer aproximar-se das obras literárias, pretende-se uma leitura agradável, considerando que a forma e a própria estética do livro se configuram como conteúdo de uma obra no campo das humanidades. Nesse sentido, mantém certa distância dos volumes brilhantes ou sisudos de algumas revistas científicas.

\section{Congressos e feiras; imagens e vitrines}

Depois de uma década de circulação, já tendo sido avaliada, em 1996, como um periódico prioritário, o que significa dizer que detinha espaço destacado entre os pesquisadores no cenário nacional, a revista, entretanto, deveria ganhar as bancas e as livrarias ${ }^{15}$. Várias tentativas foram frustradas no projeto de difusão: a busca de editoras comerciais, cujos contratos não alcançavam ultrapassar o primeiro ano, pois a natureza da mercadoria, com baixa capacidade de gerar lucros imediatos, desinteressava aos editores comerciais. Mesmo a editora da universidade não apresentou interesse pela produção e difusão da revista. Esse foi, aliás, um dos problemas discutidos no seminário sobre Política de publicação científica em educação no Brasil hoje, realizado na USP, em

14. O autor das capas da revista, de sua diagramação e dos logotipos é Milton José de Almeida, artista plástico e professor da Faculdade de Educação da Unicamp. O autor cria as capas da Revista Educação \& Sociedade e dos Cadernos CEDES, além de desenvolver estudos para capas de livros para distintas editoras.

15. A revista é citada num estudo realizado entre 1996 e 1997 como um periódico prioritário, numa classificação em que estes eram identificados como: prioritário, importante ou de importância relativa. Em 23 revistas estudadas, apenas 7 foram consideradas prioritárias. Cf. Krzyzanowski (2002, p. 87-89). 
2002, por ser um problema comum aos editores de revistas da área. A criação de um setor de distribuição próprio, embora tenha sido a melhor opção, em princípio não parecia viável. A grande idéia, nada original porque já usada por outras revistas, como Educação, Educação \& Serviço Social, Cadernos de Pesquisa, Educação \& Sociedade, entre outras, foi a montagem de stands em congressos, especialmente nos maiores e mais tradicionais, como a reunião da Anped e o Congresso de Leitura do Brasil - Cole.

A conquista de um lugar nesses espaços onde se reúnem milhares de educadores, estudantes e pesquisadores, parecia da maior relevância. E efetivamente mostrou-se importante, não para a comercialização da revista, mas para sua divulgação, para a construção da imagem, para a conquista de autores, para a garantia de visibilidade.

A importância da exposição nesse espaço de consagração de intelectuais, livros e revistas pode ser medida pela disputa, na hora de definir não só a posição do stand no barracão de exposição, mas as dimensões, a face - frente, lateral ou fundo - e a vizinhança. A disputa entre os expositores pelo melhor lugar na reunião seguinte começa logo após o término da anterior. Isso faz com que os iniciados ou os mais bem situados nas redes de relações nos espaços de poder alcancem lugares privilegiados na exposição.

Os preços desses stands também definem quem é quem nesse mercado. Eles variam de acordo com as dimensōes e as posiçōes. $\mathrm{Na}$ Anped, um stand de frente para a piscina, local onde acontecem os lançamentos de livros, onde, em geral, os congressistas encontram-se para tomar um vinho e conversar, nos intervalos entre as conferências, custa mais caro e só se consegue com domínio desse savoir faire do mundo dos congressos. Portanto, não basta poder e querer pagar o preço; é necessário domínio da informação que primeiro circula na rede de iniciados. Sorá, em seu estudo sobre a produção editorial de literatura e analisando as feiras internacionais de livros, oferece uma idéia do peso desses espaços de exposição na forma de existência de editoras e livros.

Atualmente, as feiras internacionais representam um dos espaços mais conspícuos da consagração editorial. Como rituais, mobilizam forças da publicidade e difundem técnicas econômicas, tendências culturais e uma moral profissionalizante, por meio de fórmulas que estabelecem uma matriz prática de distâncias, delimitadora do lugar que corresponde a cada autor, livro e leitor, distribuindo cada expositor de acordo com o patrimônio econômico e cultural acumulado ${ }^{16}$.(grifos do autor).

16. Gustavo Sorá (1997, p. 152). 
A revista Pro-Posiçôes entrou no universo dos congressos há quase uma déca$\mathrm{da}$, realizou um périplo até conquistar seu lugar ao sol. Primeiro seguiu como convidada, compartilhando stand com sua co-irmã, Educação \& Sociedade, uma experiência positiva para fazer a primeira socialização do representante da revista e para conhecer o espaço. Uma segunda forma de comparecer à exposição foi compartilhar o stand e seus custos com a Editora da Unicamp que, além de ajudar a preencher o espaço físico, atraía público pela sua variedade de títulos e pelo selo da universidade. Experiência igualmente positiva, embora significasse mais trabalho ao representante da revista. Por fim, hoje, a Pro-Posiçôes é exposta conjuntamente com os livros editados por docentes da Faculdade de Educação e com a revista Zetetiké. Consegue preencher um espaço médio em lugar de relativo destaque e, se não dá lucro, também não traz prejuízos econômicos.

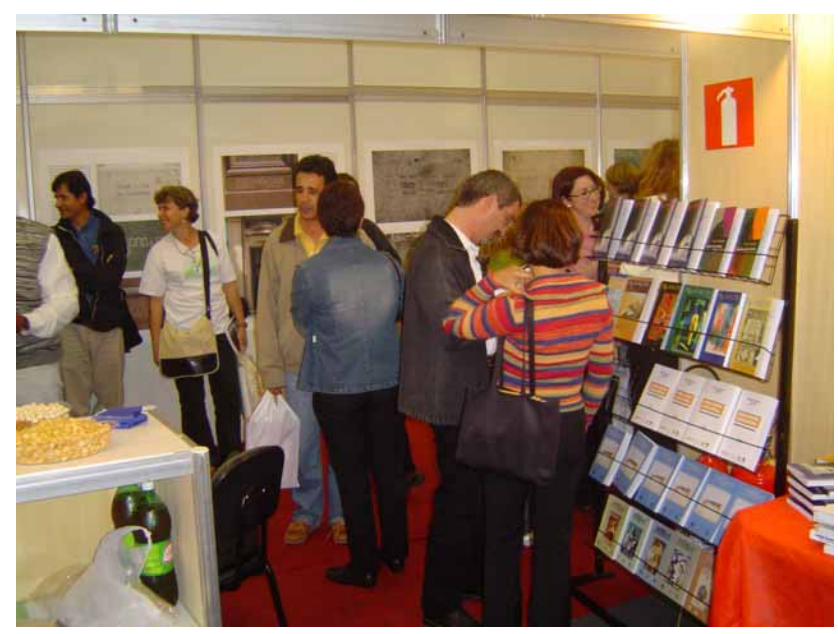

Do ponto de vista de imagem, a Pro-Posiçôes consolidou-se no espaço acadêmico da educação, é conhecida e reconhecida nacionalmente. Essa conquista alicerça-se, indubitavelmente, na qualidade do periódico; entretanto, a exposição nos congressos, os stands, os banners, as vitrines tiveram papel significativo nessa história.

Ranking, controle, criação vigiada...

Fator altamente relevante na compreensão da história de uma revista acadêmica, ligada à universidade pública, são as políticas de fomento e de avaliação, cujos impactos sobre a vida desses produtos são determinantes do lugar que ocupam. A avaliação institucional constituiu-se como disciplina e campo de pesquisa, e a criação de órgãos e instâncias oficiais para a avaliação vem ocorren- 
do em todos os níveis governamentais, configurando, para a avaliação de revistas acadêmicas, um processo complexo, no qual se envolvem distintos interesses: dos editores, das universidades, das associações científicas, dos autores e, de forma mais distante, até dos leitores.

No Brasil, os órgãos legitimados para essa tarefa são os fomentadores, especialmente Capes, CNPq e Fapesp, os quais, entretanto, atuam associados com Anped, Portal de Periódicos da Capes, SciELO, Fundação Carlos Chagas, entre outros, e apoiados sobre indicadores internacionais de circulação e citação. É quase impossível, hoje, pensar em manter uma revista, sem tomar em conta os critérios que norteiam as avaliações, pois um complexo sistema de avaliação integrada qualifica a produção intelectual, e através dela qualificam-se os programas de pós-graduação, os quais qualificam as universidades, os pesquisadores e vice-versa.

Uma afirmação de um autor que publicou na Pro-Posiçōes, em 1998, é reveladora do que estava sendo construído para a área de publicações acadêmicas. Convidado a publicar na revista, esse pesquisador — sociólogo — respondeu ao convite com a pergunta: Por que eu deveria usar um artigo meu, que pode sair numa revista qualificada, publicando aqui na revista de vocês? Só por amizade? Precisa ser mesmo muito amigo para isso. $\mathrm{O}$ artigo, enfim, constituiu o dossiê e foi publicado.

Nos últimos anos, a pergunta mais freqüente que um editor escuta dos autores é: Qual a classificação da sua revista? O que significa dizer: quanto vale o meu artigo na sua revista?, pois, dependendo do índice de qualificação da revista, sabe-se o valor do artigo nas avaliaçōes do pesquisador e de sua instituição.

Enfim, o que significa a avaliação de periódicos e qual o seu impacto? A avaliação insere-se no espaço da distinção, tão cara ao mundo dos intelectuais e dos produtos culturais. Ela adquire relevância quando o número de agentes cresce e o indicador de raridade tende a desaparecer. Sempre que algo, como a publicação de um livro ou um artigo, torna-se acessível a todos, perde o prestígio que é sempre reservado a poucos, à elite de cada campo.

Assim, nos anos 1990, assistiu-se ao crescimento das publicações em educação, associado à expansão dos programas de pós-graduação, e nesse processo os mecanismos de avaliação tornaram-se mais severos, com o fim de distinguir os periódicos, uns dos outros. A criação de espaço de debate para os editores, na Anped; os seminários e as reunióes específicas sobre o tema, nas universidades; e as publicações sobre o assunto atestam esse movimento. São os próprios pesquisadores envolvidos nas comissões de avaliação dos distintos órgãos que legitimam os mecanismos oficiais, dentro da lógica já tradicional do julgamento pelos pares. 
Dentro dessa lógica, aos editores resta a máxima: Participe ou desapareça. Algo similar ao: Publique ou pereça. Alcançar, antes dos concorrentes, as informações sobre os critérios de julgamento é a garantia de uma boa colocação nos rankings. E quanto mais bem classificado num ranking, mais chance de alcançar sucesso no outro, uma vez que um é considerado como critério para o outro. Assim, também melhor classificação assegura a publicação de autores de maior prestígio que potencializam o periódico.

Toda essa reflexão remete a um outro problema associado ao da avaliação, que é o problema do custo, da tiragem e da comercialização dos periódicos. Poder-se-ia imaginar que a expansão da pós-graduação aumentaria o número de leitores das revistas acadêmicas; entretanto, os dados não confirmam essa tese. Nas reuniōes de editores, ouve-se a mesma reclamação: estoques imensos de revistas que não circulam, pois as vendas são decrescentes. Um estudo realizado por John B. Thompson ${ }^{17}$ sobre editoras acadêmicas na Grã-Bretanha e nos Estados Unidos conclui que as edições tipicamente acadêmicas vêm enfrentando problemas há duas décadas. Uma das constatações do estudo é o desaparecimento do cliente tradicional dessas publicaçóes, as bibliotecas universitárias, o que fez sua fonte segura de recursos encolher significativamente. As bibliotecas, cujos orçamentos, como os das próprias universidades, sofreram cortes freqüentes nas últimas décadas, tiveram que fazer escolhas entre livros e periódicos, e teriam demonstrado tendência a manter as assinaturas de revistas acadêmicas, abandonando a compra de livros que não se enquadrassem na categoria de manuais. Thompson faz referência à preferência dos estudantes pelas revistas em detrimento dos livros.

Os grandes editores de periódicos científicos, como Elsevier, tomaram conhecimento do fato de que muitos universitários davam preferência às revistas, e não aos livros, para suas pesquisas. Eles, então, aproveitaram sua posição dominante no mercado de revistas científicas para aumentar os preços, ano após ano; os preços das assinaturas superaram os índices de inflaçãao ${ }^{18}$.

No caso das bibliotecas universitárias brasileiras, faltam estudos sobre o tema. Entretanto, durante o ano de 2008 e no primeiro semestre de 2009, a revista Pro-Posiçôes realizou uma campanha de divulgação por carta, com doação de exemplares da revista a mais de 500 instituições de ensino superior que mantêm curso de formação de professores, leitores potenciais da revista. Até o presente momento, o grau de resposta tem sido ínfimo, não ultrapassou $1 \%$. $\mathrm{O}$ crescimento do número de periódicos on-line pode ser um dos fatores que

17. Thompson (2006, p. 93-98).

18. Thompson (2006, p. 93, tradução livre). 
impactam a distribuição dos periódicos em papel. Todavia, ainda é cedo para ter uma posição clara sobre o comportamento dos leitores e das instituições a esse respeito.

O que, sem dúvida, fica evidente é que o lugar da avaliação ganha centralidade, dado que, quando o mercado, indicador clássico de liberdade, encolhe, a revista passa a depender de financiamentos condicionados à posição nas classificações oficiais. Dentro desse mundo vigiado e controlado, o espaço de criação restringe-se e implica um custo não desprezível. A tônica tem que ser posta sobre a negociação e sobre a inserção no campo editorial. O grande risco dessa operação é a padronização que, levada às últimas conseqüências, destrói a criação, reduz o espaço para o novo, seja na forma ou no conteúdo. Mas o maior risco talvez seja o de acreditar que o melhor da criação intelectual está registrado nos objetos mais bem classificados em qualquer ranking oficial. Enfrentar o risco de inovar, de acolher textos e temas estranhos pode ser um antídoto contra a massificação da cultura acadêmica.

A revista Pro-Posiçôes, hoje inserida na biblioteca SciELO, classificada como uma revista nível A1, o mais alto no ranking nacional, circulando em papel e on-line, terá que fazer grande esforço para manter-se como um espaço de criação e de acompanhamento dos movimentos na educação.

\section{Referências bibliográficas}

BOURDIEU, P. O mercado dos bens simbólicos. In: BOURDIEU, P. Economia das trocas simbólicas. Introdução, organização e seleção Sergio Miceli. São Paulo: Perspectiva, 2007.

DIAS SOBRINHO, J. Editorial. Avaliação, Sorocaba, v. 12, n. 2, jun. 2007.

DIAS SOBRINHO, J. Editorial. Pro-Posiçôes, Campinas, v. 1, n. 1, mar. 1990.

KRZYZANOWSKI, R. F. Critérios de avaliação de periódicos científicos brasileiros. In: BUENO, B. O.; AQUINO, J. G.; CARVALHO, M. P. de. Política de publicação científica em educação no Brasil hoje. (Org.) São Paulo: Feusp, 2002.110 p.

MIRANDA, D. B. de; PEREIRA, M. N. F. O periódico científico como veículo de comunicação: uma revisão de literatura. Ciência da Informação — Instituto Brasileiro de Informação em Ciência e Tecnologia (Ibict), v. 25, n.3, p. 375-382, 1996.

SORÁ, Gustavo. Tempo e distância na produção editorial de literatura. Revista MANA Estudos de antropologia social. Rio de Janeiro: PPGAS/Contracapa, v. 3, n. 2, p. 151-181, out. 1997.

THOMPSON, J. B. Lédition savante à la croisée des chemins. Actes de la Recherche en Sciences Sociales, n. 164, p. 93-98, 2006. 